\title{
ESTABLISHMENT OF NETWORK INFRASTRUCTURE FOR PUBLIC CONSTRUCTION PURCHASE ELECTRONIZATION IN TAIWAN
}

\author{
Sherman Li , Ho-Hsiung Yang*, and Hsueh-Wen Chiang **, H. Ping Tserng *** \\ *Associate Researcher and Section Chief, Taiwan Construction Research Institute \\ **Assistant Researcher, Taiwan Construction Research Institute \\ ***Associate Professor, Dept. of Civil Engineering, National Taiwan University, Taiwan
}

\begin{abstract}
Reasonable and up-to-date construction cost data is essential for budget making, bidding, and auditing in the construction industry. Generating a construction budget is a highly professional task and usually takes substantial time and man-hours to collect project cost data. Hence, it is always a critical point for the construction industry to set up a sophisticated cost database to improve the budgeting process, to react to price fluctuations, and to meet managerial demand.

This paper will introduce an ongoing project - 'Construction Cost Survey' -- which was launched by the Public Construction Commission, Executive Yuan (PCC), Republic of China and has been conducted by the Taiwan Construction Research Institute (TCRI) since 1996. The major points presented in this paper are the following: (1) Relevant projects which were performed by PCC and their goals, (2) The way and the channel which the project uses to acquire cost data, (3) The achievement the project has made and its web application development, and (4) Further research and work in the future.
\end{abstract}

Keywords: PCC, TCRI, Construction Cost Survey, Survey Mechanism, Public Construction Technical Database, Construction Cost Database, Dynamic Web Page, XML.

\section{Introduction}

The materials, equipment and machines, Labors and the purchase of items between subcontractors involved in the whole process of job execution in the construction industry are numerous and complex and the amounts of purchase are usually enormous. Thus, purchase and budgeting have become an important part in the management of the construction industry. Therefore, the key point for increasing the performance of overall management is how to efficiently obtain reasonable and up-to-date cost data, improve the inefficient procedures in the purchase process and enhance the value chain of the overall budgeting and purchasing.

Traditionally, the budgeting and purchase processes in the construction industry are extremely complex and the people and procedures necessary as well as time and cost consumed are considerable. These include the cost for collecting and analyzing data of products to be purchased, cost for data establishment and budgeting, cost for internal finalizing and transaction payment and indirect costs such as delivery and acceptance inspection. The aforesaid purchase-related costs in aggregation are even several times higher than the costs of products to be purchased. This is also the reason why companies lose their competitiveness.

Since it started to influence people's lives, the Internet's influence has gradually expanded from individual consumption and entertainment to corporate operation and management in individual industries. Thus, increasing the efficiency in budgeting and construction purchase through the use of the Internet has become an important issue for the construction industry in Taiwan. This paper will introduce the "Construction Cost Survey" launched by the Public Construction Research Institute (TCRI), its work, the current state of its application on the network as well as the prospect and direction of future works.

The second section of this paper will introduce the two programs launched by the Public Construction Commission, Executive Yuan (PCC) which greatly help increase the efficiency in budgeting and construction purchase - "Integration of Public Construction Technical Database" and "Governmental Purchase Electronization" -- and describes the correlation between the "Construction Cost Survey" and the two programs. The third section is to introduce the work mode of the "Construction Cost Survey". The fourth section will describe the current state of the application of the "Construction Cost Survey" on the Internet and discuss possible directions for the development of Network Standards for the Construction Industry in the ROC. Finally, we will discuss the directions for future development of the "Construction Cost Survey" and the picture of the future development of TCRI on the Internet establishing the Purchase Information Website for the Construction Industry and further expanding it into the Portal Website for the Consturction Industry in Taiwan. 


\section{Summary on Governmental Purchase Electronization and Integration of Public Construction Technical Database}

In recent years, Taiwan's government has actively promoted technological R\&D, industry assistance, technical realization, popular education and creation of an Internet-friendly environment. To open the gate for the entry of the vast commercial field in Taiwan into the field of e-commerce, set a good example for the electronization and network of the government administration, and lead the private sector to realize the vision of Asia Pacific Technology Hub, the government has planned and implemented the "Government Purchase Electronization" to form the economic scale of network purchase and thus encourage the development of relevant technologies and techniques.

Meanwhile, public construction has always been a vital force in Taiwan's economy. To realize the standardization and transparency of the procedures of government construction projects, the government has also implemented the "Integration of Public Construction Technical Database". The aforesaid plans will be summarized in Sections 2.1 and 2.2.

\subsection{Government Purchase Electronization}

The implementation and realization of the "Government Purchase Electronization" is expected to improve the operations and processes related to government purchase, reduce costs related to purchases of governmental agencies and increase administrative efficiency through advanced information communication technology and environment.

\subsubsection{Strategies for Implementing}

\section{Government Purchase Electronization}

Government Purchase Electronization is a brand new experience and an administrative goal with a high level of difficulty. It requires proper planning and scheduling of implementation. Within the scope of existing regulations, policies and overall environmental limits, the PCC has set up a series of strategies for implementing the Government Purchase Electronization to create a convenient, fair, impartial, open and secure operating environment for purchase electronization to reach the policy objectives:

(1) Major works include leading policies, establishing codes and standards, developing common software tools and studying regulations for the elements that the private sector is unable to create and which require the intervention of governmental authority.

(2) Systems placing emphasis on easy-to-use automated and manual operations with low setup costs.

(3) Those that do not contradict the existing regulations and can be developed with existing technologies are given priority in implementation.

(4) Create relevant application systems in line with the schedule for implementing government electronization.

(5) Effectively use external resources (such as overall outsourcing of information).

(6) First apply to purchases of smaller amounts and high repetition for testing.

(7) First select agencies with stronger information capabilities for testing and then gradually extend the application to other agencies.

\subsubsection{Government Purchase Electronization}

According to the aforesaid seven instructional principles for strategy implementation, the "Government Purchase Electronization" planned by the PCC covers six major work axes (Figure 1). The "Government Purchase Information Announcement System" includes an enormous amount of information related to government purchases, making it convenient for suppliers and the public to make online inquiries. The implementation of the alreadycompleted "Electronic Supplier Directory System" and the "Electronic Inquiry and Offer by Suppliers System" can achieve benefits such as simplifying the procedures of government purchases, reducing purchase costs, increasing purchase efficiency and fully disclosing purchase information, etc. Electronic systems such as "Joint Supply Contract Announcement System", the "Electronic Bid Receiving and Bidding System" and the "Electronic Ordering and Payment System", which are currently being planned and implemented, can effectively integrate purchase procedures of governmental agencies with common needs, reduce purchase expenses and avoid wasting manpower.

The current state of work on each axis is described as follows:

(1) the Government Purchase Information Announcement System

(2) the Joint Supply Contract Announcement System

(3) the Electronic Supplier Directory System

(4) the Electronic Inquiry and Offer System

(5) the Electronic Bid Receiving and Bidding System 


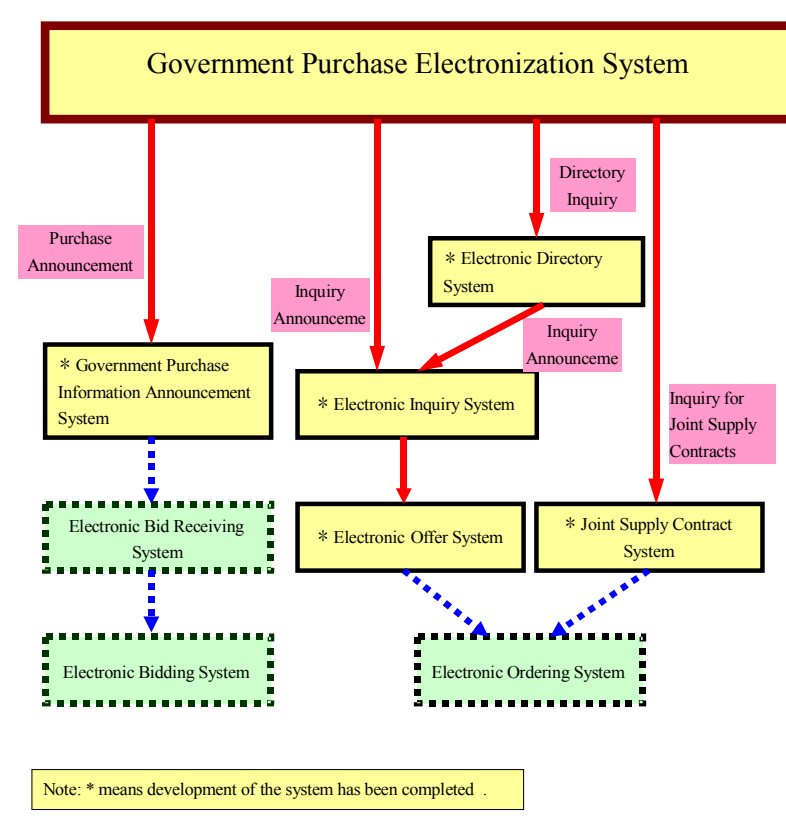

Figure 1 Correlation Diagram of Systems related to Government Purchase

\subsection{Integration of Public Construction}

\section{Technical Database}

The purchase contracting for public construction takes up a large proportion of the government budget each year and thus is an essential field for realizing government purchase electronization.

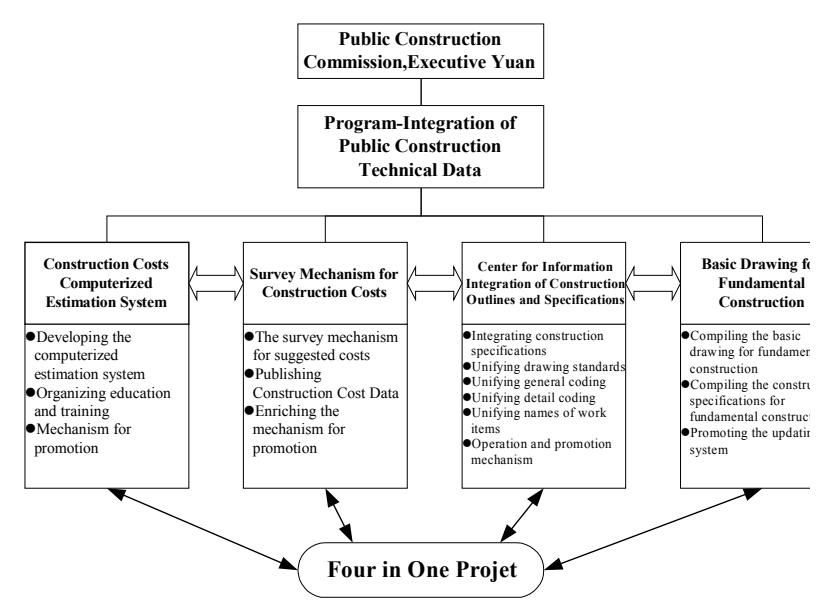

Figure 2 Project - "Integration of Public

\section{Construction Database"}

To realize the transparency of public construction operations, procedure systemization, accurate detailing of expenses, management professionalism and technical internationalization, the PCC has planned and implemented the project -
"Integration of Public Construction Database". Under the project, there are four axis sub-plans (as shown in Figure 2): the "Public Construction Specification Compilation and Information Integration Center", the "Plan for Compiling and Promoting Basic Drawing for Fundamental Construction", the "Plan for Promoting the Public Construction Costs Computerized Estimation System" and the "Creation of Public Construction Resource Cost Database and Survey Mechanism". Their functions and structures are correlated and the causal relationship is mutually complementary (details shown in Figure 3).

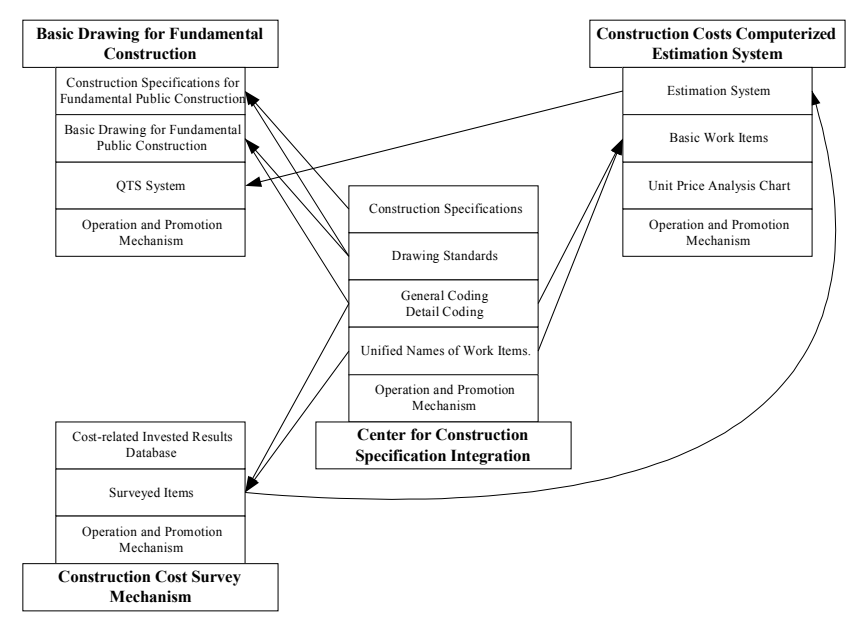

Figure 3 The Four in One Project Correlation

\subsubsection{Public Construction Specification Compilation and Information Integration Center (Construction Specification Compilation Center)}

The purpose of setting up this organization is to deal with issues such as realizing the creation and organization of the compiling framework for the work items in construction outline specifications, unifying measures for names of work items, coding and engineering drawing standards and so forth, as well as results of implementation that affect the contents of public construction cost estimations and quality recognition standards, etc. The organization is also responsible for integrating the results of implementing each sub-plan and coordinating the opinions within the industry, the government and academia.

At present, the organization has achieved the principles for public construction outline specifications, engineering general coding and detail coding for the use of the other sub-plans in this Four in One Project. Subsequently, the organization will gradually extend these principles to various construction projects to create the local construction technical specifications in Taiwan. 


\subsubsection{Basic Drawing for Fundamental Public Construction}

The plan "Basic Drawing for Fundamental Public Construction" is to make standard manuals mainly subject to engineering design and construction drawings, work item breakdown, cautions and so forth for fundamental public construction such as mud buffer facilities, public roads, sewage, etc. These manuals can be used in combination with the public construction outline specifications compiled by the Construction Specification Integration Center for actual ongoing construction.

If actually promoted and realized in various levels of local governments, the standardization of engineering drawings and construction operations derived from the compilation of basic drawings can largely increase efficiency in fundamental construction.

\subsubsection{Public Construction Costs Estimation System (PCCES)}

The main functions of the "Public Construction Costs Estimation System" (PCCES) are to execute "construction costs estimation, budgeting and contract making etc." in stages such as planning, design and subletting for public construction. It can also meet the demands of stages in construction by implementing construction control, examination and feedback correction, etc.

The "Basic Drawing for Fundamental Construction" in the Four in One Project provides users with functions like standardized engineering section design and material quantity calculation, etc. The "Public Construction Material and Work Item Prices Database" (also known as the "Construction Cost Survey") allows the PCCES to directly shift to operations and applications necessary for the processing of resource price data and also has the benefit of prompt updates of price data.

\subsubsection{Creation of Public Construction}

\section{Material and Work Item Prices}

Database and Survey Mechanism

\section{(Construction Cost Survey)}

This sub-plan is mainly to achieve the goals of collecting and announcing price data of material items in public construction. It is necessary to cope with the unified specification names and work item coding achieved by the "Public Construction Outline Specification Compilation and Information Integration Center", create the material price database and the interface of relevant information operating systems, facilitate the integrity of applications of plan results and increase the efficiency of information operations.

\section{Execution of Construction Cost Survey and Database Creation}

As can be seen from the aforesaid, the results of implementing the Material and Work Item Prices Survey Database and Survey Mechanism (the Construction Cost Survey) are the key for the integration of public construction technical databases (see Figure 3). The contents of the plan are described in detail as follows:

\subsection{Organizations and Mode for Survey Activities}

To promote the creation of construction costs survey mechanisms and activities, the PCC entrusted TCRI with the task of launching the "Study on Construction Cost Survey" in January 1996. The "Construction Cost Survey" actually started in December 1996 and TCRI set up the "Construction Materials Survey Section" to be responsible for activities related to the survey and study.

\subsubsection{Organizations for Survey Activities}

The survey organizations in the study as a whole are divided into three parts: the external examining organization, the internal operating organization and the external consulting and assisting organization. Figure 4 shows the organizational chart for implementing the construction cost survey.

\subsubsection{External Examining Organization}

This includes the Construction Specification Integration Center and the External Examination Commission. The Center is organized by the Engineering Technical Consulting Industry Association of the R.O.C. as designated by the PCC and its purpose is to integrate construction specifications and construction coding. The resource coding of selected survey items in the process of the Construction Cost Survey shall go through the examination of the Center. The External Examination Commission is set up to examine the credibility and information quality of the survey implementation. 


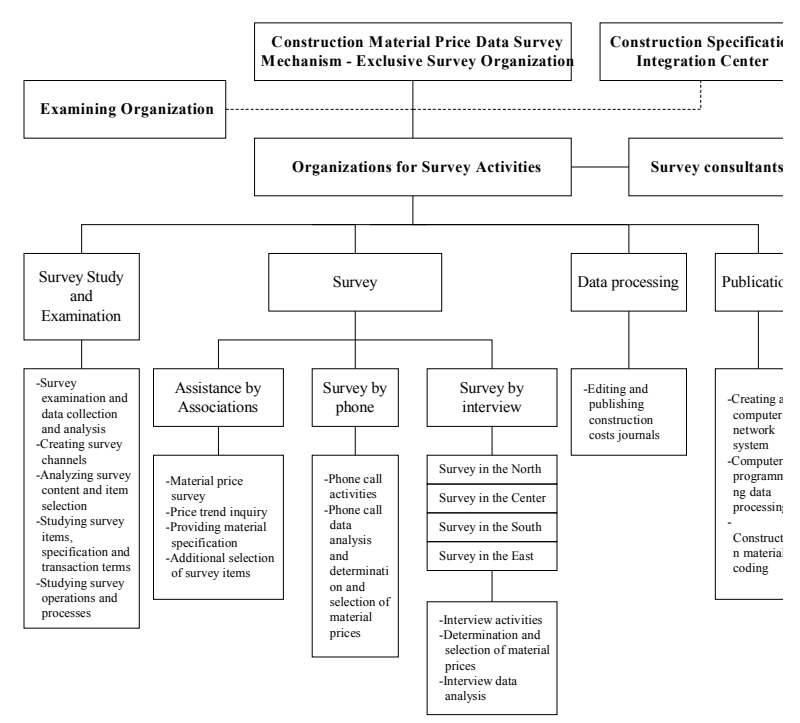

Figure 4 Organizational Structure of Construction Cost Survey

\subsubsection{Internal Operating Organization}

This mainly consists of the Construction Materials Survey Section of TCRI and deals with survey studies, survey activities, information processing, and publication as well as education and promotion. At present, there are about 20 staff members engaged in the construction materials survey.

\subsubsection{External Consulting and Assisting Organization}

As the construction costs survey involves a wide range of professional fields, how to combine professional, objective and enthusiastic people in the construction industry to expand the foundation for the survey has always been one of the main concerns in implementing the survey. At present, in addition to inviting several experts from various professions such as agricultural, electrical, and civil engineering and architecture as consultants, the "Construction Purchase Association" has been set up and surrounding entities such as the meeting of Construction Cost External Examination Commission have been held to combine the efforts of enthusiastic and professional people to assist the implementation of the survey in the long run and to expand the survey foundation.

Combining groups of experts and consultants in assisting organizations has helped the overall construction costs survey a great deal and is the best way of simplifying organization and manpower to assist in the acquisition and analysis of professional information and confirmation in the final price examination.

\subsubsection{Methods for Implementing Survey}

\section{Activities}

The methods for implementing survey activities are described as follows:

(1) Main body of survey: market prices of labor, equipment and machines, materials and elemental work items unit prices used in construction projects.

(2) Survey cycle: Before 1998, the survey was done in a quarterly basis. Since 1999, it has been done once every other month. In addition, prices of important resources are surveyed and announced on the Internet in a monthly basis.

(3) Sampling method: sampling by layer Divide the whole province into the north, the center, the south, the east and main offshore islands (Penghu and Kinmen) and implement respective surveys. Voluntary sampling is used and the responsible staff for each region selects the targets for the price survey.

(4) Survey samples: In principle, survey five samples respectively from resource providers and users. If the sample number needs to be adjusted due to different usage of resources, the adjustment shall be announced in the "remarks" column of each listing of price information.

(5) Survey method: Survey by face-to-face interview, fax and phone for resource providers and survey by face-to-face interview and mailing for resource users.

\subsubsection{Methods for Selecting Prices in Survey \\ Data}

After large amounts of sample data is collected, the announced values must be determined through statistical analysis processing and the basic principles for selecting announced values are as follows:

(1) For price fluctuation trends, resource providers are most capable of responding to them within shortest time while resource users for the most part cannot grasp price changes within a short time.

(2) The sequence for determining the representative values in the valid sample groups is:

- mode principle ( $40 \%$ valid sample value)

- mean principle

- median principle 


\subsection{Results of Implementation}

The results of implementing the survey and data collection planned by the Survey Mechanism are respectively the results of price data survey, results of relevant data collection and analysis as well as the application and promotion of plan results. These are described below:

\subsubsection{Results of Price Data Survey}

Testing survey on suppliers and market research are performed before the survey on such price data in each term. After procedures such as selection of survey times, specification establishment and setting of price measuring units, transaction channels and transaction terms etc. have been reviewed, a survey addressing to each survey region is performed by phone, fax or interview to obtain the sample data of latest market price of each survey item. Then, the representative value of surveyed prices for each survey item in each survey region is established as the main result of the survey. At present, the "construction cost survey" has been performed for 18 times with over 3,200 survey items. Over $95 \%$ of the items are converted according to the reporting index weight of the Statistics Department. The resulted data of price survey is published in the bimonthly journal Construction Cost for the reference of the public.

\subsubsection{Results of Relevant Data Collection}

\section{and Analysis}

To provide more diverse information for public reference, government-related information, information on internationally important resources, information from associations, societies and the press as well as bid archives of government agencies are compiled for statistical analysis.

\subsubsection{Government Information}

Such information is mainly obtained from the statistics compiled and announced by government agencies. In this stage of the plan, the information extracted includes the "Construction Price Index" from statistics units, the "Construction Statistics in Taiwan" from the Construction Bureau, the Interior Ministry, and the "Information on Leftover Construction Gravel in Taiwan" from the Industry and Technology Research Institute.

\subsubsection{Information on Prices of}

Provide information on important imported construction materials related to the industry such as the market prices of "Construction Material Costs" from Japan and information on the main resources (steel products, cement and gravel etc.) for construction pricing from Shanghai, China.

\subsubsection{Information from Associations and}

\section{Societies}

This information is obtained from statistics of the private sector. In this stage of the plan, the information extracted includes the announced statistics of material circulation quantities and the market price list provided by societies.

(1) Statistics on material circulation quantities by associations: Construction Cost publishes the charts based on statistical information on mass materials such as steel products and cement etc. Compiled by individual associations. The purpose is to explain possible causes of price fluctuations, respond to the variations in construction cost structure or predict price fluctuations in addition to understanding relevant statistical information.

(2) Market price list by societies: This is provided by the PCC to relevant associations and societies for price information exchange in order to extend the range of service and publishes the up-to-date market price information for the reference of the public. In addition, market price information provided by Taichung City Architecture Quality Control Society, ROC Curtain Wall Technical Development Society and Taiwan Cement Product Industry Association etc. to their members is also obtained. In the market price list provided by the aforesaid societies, building material prices, elemental work items unit prices and prices for electrical and fire-fighting equipment and so forth necessary for the construction industry can mostly be found, so it is of considerable value for the reference of the construction industry.

\subsubsection{Information from Associations and}

\section{Societies}

In each issue, "Construction Cost Data" continues to extract press information and compile reported data regarding prices of steel products and building materials common in the construction industry into statistical charts and convert them into trend diagrams for the reference of the industry.

\subsubsection{Statistical Information from Bid}




\section{Archives of Government Agencies}

Data from bid archives are a very important reference for construction budgeting. With the assistance of the PCC, price data from bid archives regarding project subletting by individual construction units is collected for statistical analysis. The bid archive elemental work items unit price database is created with reference to the 21 categories of construction projects classified by the Construction Specification Integration Center of the PCC for the reference of individual users for construction budgeting.

\subsubsection{Significant Milestones in Plan}

\section{Implementation}

(1) The preliminary draft of the survey theory study and survey organizational structure was completed in May 1996.

(2) The "Construction Materials Survey Section" was set up in November 1996 to implement the construction materials survey and lay the initial foundation for the setup of the "Construction Resource Information Center".

(3) Issue No. 1 of the quarterly "Construction Cost Data" was published in February 1997, 56 pages in total covering labor, equipment and machines, and materials and 176 entries in total of construction resource price data.

(4) The Executive Yuan approved the four-year midterm plan "Creation of Public Construction Price Database and Survey Mechanism" in January 1998 as a solid and firm support to the construction costs survey.

(5) Issue No. 5 of the quarterly "Construction Cost Data" went on sale publicly in March 1998 (the first four issues had been issued free of charge) and the initial subscription exceeded 3,000 copies.

(6) The publication of "Construction Cost Data" changed from quarterly to bi-monthly (one issue in each odd month) in September 1998. The survey cycle for important resource items was also shortened to one month and the survey results were announced on line.

(7) In March 1999, "Construction Cost Data" provided the statistical information of bid archive elemental work items unit prices as reference for budgeting.

(8) In April 1999, "Construction Cost Database Inquiry System" went officially on line to provide users with a prompt 24-hour inquiry service.

(9) In October 1999, the plan "Creation of Public Construction Price Database and Survey Mechanism" was included in the Four in One Project - "Public Construction
Database Integration" and its implementation was continued.

(10) In February 2000, the bimonthly journal

"Construction Cost Special Issue" was published to provide promptly updated price information on a monthly basis.

(11) By July 2000, the construction cost survey had already been performed for 18 times with over 3,200 survey items and over 5,000 subscribers.

For the implementation of the plan, in addition to regular publication in Construction Cost and "Construction Cost Special Issue", a professional website (http://www.tcri.org.tw/) was set up on the Internet for promotion. It is expected to assist the government achieve the goals of price transparency and information disclosure and lead the construction industry to enter the e-tide in the 21 st century by taking advantage of the far-reaching and boundaryfree nature of the Internet.

\section{Technical Development of Construction Cost Network}

\subsection{Introduction to Existing Internet}

\section{Technology}

In recent years, e-commerce has become a global fad. As the numbers of people on line have increased greatly and corporate electronization has become widespread, e-commerce websites not only have become the mainstream, but have also encountered new challenges. Static web pages can no longer meet the demands of clients and customers. To create a successful dynamic e-commerce website, it is a must to obtain product and client data and rapidly link the existing static web page to the database.

Hence, the technology of dynamic web pages is becoming increasingly important. At present, common websites generally use the platformstraddling PHP3 (Personal Home Page III) on Apache Server, ASP (Active Server Pages) on Microsoft NT Server, and the Java-based, platform-straddling JSP as the main technologies for dynamic web page programs. The so-called "dynamic web page program" is a kind of application that allows the use and application of web pages on the web server and sends the results translated by the server (standard HTML texts) in a dynamic way to the client. Hence, no compatibility problems with the browser at the client's end will occur. Its executing efficiency, unlike the dynamic CGI (Common Gateway Interface) program used in the past, will not crash the server due to too many users being on line at the same time. In addition, the system design and maintenance of the dynamic web page program are not like those of CGI, which are plotted and written independently from 
HTML texts, so the efficiency in development and revision is largely increased. Moreover, for suppliers to be able to perform secure and prompt inquiries and offers, it is necessary to add the SSL (Secure Sockets Layer) security transmission function to avoid data transmitted on the net from being intercepted or interpolated and provide website managers and clients with proper security.

\subsection{Current State of Application of "Construction Cost Database" on the}

\section{Internet}

To extend the applicable range of the Construction Cost Database, and enable users' inquires to be answered more promptly, in addition to static web page information on the Internet, the Construction Cost website also provides various dynamic web page value added services such as the Construction Cost Database Inquiry (building materials and elemental work items), monthly surveyed price information on important resources, construction general calculation and bid archive unit price information, etc. to enable users to enjoy the convenience of 24-hour prompt inquiry via the network technology in addition to the option of press journals. The initial construction of this dynamic exclusive website is at present completed and about 2,000 people on line browse the website each month. The construction technique of the dynamic web page and current plotting of the website are described below:

\subsubsection{Description of Construction Technique of Dynamic Web Page}

As the website's server uses Microsoft NT system, the dynamic inquiry system of the Construction Cost Website adopts the three-tier Web Dynamic Page Technical Structure of Microsoft Windows DNA (Distributed interNet Application) and the three tiers are respectively the presentation tier (HTML +CSS +JavaScript), business logic tier (HS4.0+ASP+COM), and data service tier (SQLServer). Users can be connected to the website server and the database server at the back end through a common browser. The website server will promptly display the results of user inquires.

\subsubsection{Current Website Plotting}

At present, the exclusive website has initially provided relevant dynamic web page functions like up-to-date information on the construction market, a 24-hour on-line subscription service, links to construction-related websites, general coding inquiry and an interactive message bulletin. At present the databases on line are mainly as follows:

(1) Construction Cost Database Inquiry

(2) Bid Archive Elemental Work Items Unit
Prices Database Inquiry

(3) Public Construction Bids General

Calculation and Analysis Information Inquiry

(4) Important Resource Monthly Surveyed Prices Database Inquiry

(5) Kinmen and Penghu Important Resource Price Information Database Inquiry

(6) Taichung County Elemental Work Items Unit Prices Database Inquiry

(7) Building Material Suppliers Database Inquiry

\subsection{Possible Directions of Future}

\section{Development}

\subsubsection{Trend of Information Exchange}

Standard (EDI to XML)

XML (eXtensible Markup Language) is a language for Internet and Web defined data exchange standards. XML is the simplified form of the traditional SGML, but is more flexible than HTML. Users can customize tags and use it for transmitting structured data. XML plays an important role in ecommerce, especially B2B e-commerce transactions.

At present, a common HTML document includes content and display tags. However, most tags are not completely structured and it is hard to understand their meanings. Thus, it is not easy to obtain data from them. As the EDI (Electric Data Exchange Standard) files used by the construction industry for years do not store data in a structured manner, it is not easy to obtain data through the Internet. However, XML is a structured, well-formed document. All the tags have meanings and it is possible to define one's own tags depending on different needs. The defining method includes DTD (document type definition) and XML Schema. The two methods are similar to the process of designing relational database modules related to the E-R Model entity and defining field names or property of table in the general plotting of database application systems. Only now the data is plotted in the XML document so that different users can both retrieve and save XSL (eXtensible Stylesheet Language) + XML documents through the Internet.

Using standard and structured XML documents is the most effective way to enable users to convert large amounts of Internet document data for corporate internal use or entry into databases. If a lot of corporate internal data needs to be transmitted on line for common use, it is necessary to re-enter it into the tables on the web page and store it in the sharing database through ASP, which is not very economic. Hence, if the common XML standard can be used for re-storing data among companies, the companies can exchange and share data through the Internet. At present, technically one can convert the data to be 
shared in the database through the dynamic web page program technique (such as ASP, PHP3) at the server end. The completed XML documents are then parsed into HTML by the Web Server coping with XSL documents and transmitted to users or XSL+XML documents are directly transmitted for use under the support of the user browser. Hence, it should be no problem technically. However, specifying a common XML Schema data exchange standard for B2B in the construction industry is a major issue that needs further discussion.

\subsubsection{Future Planning of the Construction \\ Cost Website}

At present, those using XML as the data exchange standard for launching system creation are the Supplier On-line Offer System, Individualized Price Inquiry Tier, Elemental Work Items Unit Prices Inquiry, etc. The On-line Decision Analysis System will be added in the future so that it will be possible to promptly analyze the price trends and movements in the construction market. The contents of each system service are as follows:

(1) Supplier On-line Offer System (SSL security confidential): Suppliers can register to become on-line offer members. In addition to on-line offers of fixed offer items based on the supplier classification, members can also inquire about and promptly obtain statistics on offers by other suppliers.

(2) Individualized Price Inquiry Tier: Users can customize the Elemental Work Items Unit Prices, level of rise and fall and relevant construction information that they want to browse each time on line. When the prices of the work items in the Construction Cost Database change, the system can be set to promptly inform users via e-mail.

(3) Elemental Work Items Unit Prices Inquiry: In the future, the contrast operation will be performed among work items, public construction basic drawings and cost databases of individual units in line with several important common elemental work items breakdown manuals (such as Taipei Municipal/ Kaohsiung Municipal MRT Bureaus and Railway Bureau) Then, the elemental work items unit price database is constructed for users to be able to perform prompt on-line combined unit price analysis inquiries.

(4) On-line Decision Analysis System: At present the Construction Cost Database has accumulated over 70,000 entries of archived statistical price data. It will be more convenient for users to perform price estimations of various construction resources and elemental work items and use as the determining basis in the estimation and examination if the inquiry can be combined with the prompt on-line analysis and decision function.

\section{Conclusion and Future Prospects}

TCRI has conducted the construction costs survey for three years so far. Over 3,200 common resource items in public construction have been collected and compiled for survey analysis. Over 370 pages of the bimonthly Construction Cost have been published for the reference of individual government agencies and construction businesses. We have also established the preliminary survey organizational structure and the implementing procedure and mode. However, compared to decades of experience in implementation, well-equipped organizations and various closely cooperative systems in Japan, USA and South Korea, the "construction cost survey" in Taiwan still has considerable room for further efforts. The implementation and continuing management of the "construction cost survey", in addition to the large amounts of manpower and resources, requires close cooperation, support and participation of construction-related industries. The following represent the directions for the implementation of the survey in the future:

\subsection{Enhancing the intention of construction- related industries for cooperation}

The construction costs survey is a task that consumes lots of manpower and resources while the information quality relies on the actuality of original data. Hence, the willingness of construction-related industries to cooperate is the key to the long-term implementation of the work. Initially, constructionrelated business owners were reluctant to cooperate with the implementation of the construction costs survey. Recently, the situation has improved as the construction industry has become familiar with the work. However, overall, there is still room for further enhancement.

\subsection{Improving data collecting and processing procedure}

It is true that the study has completed the development of automatic statistics, survey data analysis and the publication of the software system. However, the publication of the survey journal once every other month with over 3,200 survey items and several tens of thousands of original data entries required for processing in each issue still results in a burden to personnel and pressure to meet the work schedule. Hence, the effort and time invested in the data collecting and processing procedure is considerable. It is necessary to simplify the processes for surveying and data processing through computer technology so as to increase the operating efficiency 
and solve the problem of manpower and time regarding data collection and processing. Otherwise, in the future increasing amounts of data will inevitably lead to bottlenecks in implementation of the work.

\subsection{Facilitating the creation of the}

\section{"Construction Information Center"}

Over three years of implementing the construction costs survey, the survey organizations have acquired an overall understanding of and contact with the construction industry. The existing survey organizations can be further extended and elevated into the "Construction Information Center" if relevant researches and surveys can be combined. The Center can perform collection, analysis and compilation of information on the construction industry and provide the public construction industry with information necessary for planning and decision-making, budget estimation, subletting and purchasing as well as R\&D through regular announcements in "Construction Cost Data". Thus, it can achieve the goal of enhancing the overall public construction budgeting and application control.

\subsection{Developing and creating the gateway website for the construction industry}

In recent years, as the government enthusiastically encourages development by its policies, the external environment for e-commerce has, for the most part, been well established and equipped. In addition to the popularity of the Internet, low pricing of computer equipment and prosperity of relevant technologies, the competition among service and solution providers is fierce. The construction industry can enjoy the existing benefits if it rides this e-tide at this time.

Planning of the construction gateway website should include comprehensive and abundant industry-related information such as constructionrelated regulations and codes, government and private purchase information, construction engineering techniques, construction drawings and electronic directory, industrial expert database, human resources and machine resources, construction news, etc. to attract people engaged in construction to browse the website and search for the desired information. In addition, the website provides the suggested multi-functional platform tier system to recruit members for developing construction network groups. The groups can use functions like collaborative sublet, joint purchase, technical service providing, etc. to create an e-commerce economic trend in the construction industry.

TCRI, using the existing construction costs website as the foundation, is planning to set up a regional construction gateway website in Taiwan and further develop it into the "Asia Pacific Construction Network" aiming at the international community by integrating the construction e-commerce markets in the Asia Pacific region. We hope that the network can become part of the "Asia Pacific Technology Hub" to be established in Taiwan.

\section{Bibliography}

[1] Lin Neng-Bai, Chen Cheng-Chuan and Guo Rui-Hsiang: "Study on Construction Cost Survey", Report of Project Study Results by PCC, 1996.

[2] Wei Yen: "Creation of Public Construction Fabrication Price Database and Survey Mechanism" (No. 1), Report of Project Study Results by PCC, 1997.

[3] PCC "Public Construction Cost Estimation and Budgeting Manual”, publication of PCC, 1998.

[4] Hsieh Ming-Rui, "1997 Survey Report of Construction Price Index Weighted Number Structure", Report of Project Study Results by Statistics Department, Executive Yuan, 1997.

[5] Lee Hsiao-An: "Creation of Public Construction Fabrication Price Database and Survey Mechanism" (No. 1 1998), Report of Project Study Results by PCC, 1997.

[6] Lee Hsiao-An: "Consolidating the Construction Environment - Implementing Construction Cost Survey", Civil and Irrigation Journal, Vol. 25, No. 1, 1998, pp. 102-115.

[7] Lee Hsiao-An, Wang Guo-Cheng: "Creation of Public Construction Fabrication Price Database and Survey Mechanism (1999)", Midterm Report of Project Study Results by PCC, 1998.

[8] Chen Wu-Chiang: "Analysis of Current State and Application Prospects of Government Electronic Purchase Operating System”, Electronization and Informationalization of the Construction Industry, TCRI, pp. 75-89, 1999.

[9] Chang Jung-Chi, "Current State of Implementing Government Purchase Electronization in Taiwan", 1999 Annual Convention Thesis Collection of ROC Civil and Irrigation Engineering Society, pp. 129135, 1999. 